\title{
Lipofilling (fat grafting) in the secondary prevention of ischial tuberosity and pelvic pressure ulcers
}

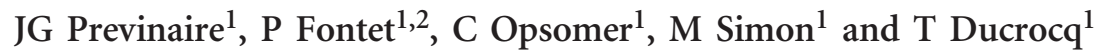

Study Design: Retrospective study.

Objectives: Lipofilling was proposed to adult chronic spinal cord injury patients with history of ischial tuberosity pressure ulcers surgery, at risk of recurrence of pressure ulcers due to unsatisfactory adipose tissue thickness.

Setting: Fondation Hopale, Berck, France.

Methods: The three staged (Coleman) procedure for fat grafting consisted of water-jet assisted liposuction (Harvest-Jet), decantation, and reinjection of the autologous fat in three-dimensional plan.

Results: Ten consecutive patients (eight paraplegics and two tetraplegics) benefited from bilateral ischial lipofilling, with additional lipofilling of the sacrum (three patients) and the trochanters (two patients). All patients attended the seating clinic with pressure mapping before and after lipofilling for appropriate cushion prescription. Mean follow-up time was 16 months (4-24 months). Complications were limited to stage I (two patients) and stage II (one patient) pressure ulcers, due to negligence. Excellent results with minimal fat wasting (between $10 \%$ and 25\%) underneath the ischial tuberosity were seen in eight patients, with significant improvement of adipose tissue thickness. Total fat waste was seen in two patients, one of whom following dramatic weight loss. Results were always good in the sacrum and trochanteric areas. Lipofilling allowed longer sitting times (three patients), improved skin quality (nine patients), improved quality of life (six patients), 'a better feeling of positioning in their wheelchair' (four patients), and decrease in pelvic pain (three patients).

Discussion and Conclusion: Pelvic lipofilling is safe, cost-effective, and can now be considered in the primary prevention of pelvic pressure ulcers in patients with insufficient adipose tissue.

Spinal Cord (2016) 54, 39-45; doi:10.1038/sc.2015.184; published online 20 October 2015

\section{INTRODUCTION}

Pressure ulcers (PrUs) are a serious, lifelong secondary complication of spinal cord injury (SCI) that have the potential to interfere with physical, psychological and social well-being and to impact overall quality of life. ${ }^{1}$

A $\operatorname{PrU}$ is a localized injury to the skin and/or underlying tissue usually over a bony prominence, as a result of pressure, or pressure in combination with shear. A number of contributing or confounding factors are also associated with PrUs, the significance of which has yet to be elucidated. ${ }^{2,3}$

When sitting in a wheelchair, the ischial tuberosity is one of the most vulnerable sites for PrUs formation. Up to $85 \%$ of adults with SCI will develop a $\operatorname{PrU}$ at some point during their lifetime, with an estimated $36-50 \%$ of PrUs resulting from sitting in a wheelchair. ${ }^{4}$

There have been numerous recommendations for the prevention of PrUs post SCI, with appropriate diet, pressure relief practices and wheelchair cushion selection playing a major role. ${ }^{1-3}$

Treatment of ischial tuberosity PrUs remains challenging. Once a $\mathrm{PrU}$ has begun, standard wound management associated with partial or total sitting restriction and cushion selection are sometimes not effective enough to prevent worsening. The evolution of ischial tuberosity PrUs is often dramatic: in a study in veterans with chronic
SCI hospitalized for PrUs, pelvic PrUs (including ischial tuberosity) were most frequently categorized as stage IV in $73 \%$ of cases, $34 \%$ of these ulcers were infected, and $40 \%$ had undermining of adjacent tissue. $^{5}$ In those cases, surgical reconstruction becomes the only available option. Different types of muscular flaps with varying degrees of vascularization and tissue layers can be chosen to match the type of wound and the defect type. ${ }^{3}$ However, as PrUs of the buttock regions are often large, surgical flaps are not always effective to provide enough deep tissue cushioning, that is, unsatisfactory skin and adipose tissue thickness. This is one of the reasons explaining a recurrence rate after surgery in the range of $20 \%$.

The correction of soft tissue defects has always been a challenge for plastic surgery. Besides silicone implants, fat grafting has become increasingly popular in the past 10 years, especially for breast reconstruction or augmentation. Fat has many properties that render it an ideal filler. It is autologous, soft, frequently abundant and easily collected, but it is not inert: injection of fat in tissue may change the microenvironment by the addition of multipotent cells and stimulating factors. ${ }^{6-12}$ Recently, fat grafting has been described for the treatment of early stage ischial or sacral pressure ulcers in patients with SCI and other chronic bedridden patients, with good results at 3 months follow-up. ${ }^{13}$

${ }^{1}$ Spinal Cord Department, Centre Calvé, Fondation Hopale, Berck sur mer, France and ${ }^{2}$ Aesthetic and plastic reconstructive surgery, Centre Calot, Fondation Hopale, Berck sur mer, France

Correspondence: Dr JG Previnaire, Centre Calvé, Fondation Hopale, 62600 Berck sur mer, France.

Email: preving@@opale.com

Received 26 May 2015; revised 27 August 2015; accepted 10 September 2015; published online 20 October 2015 

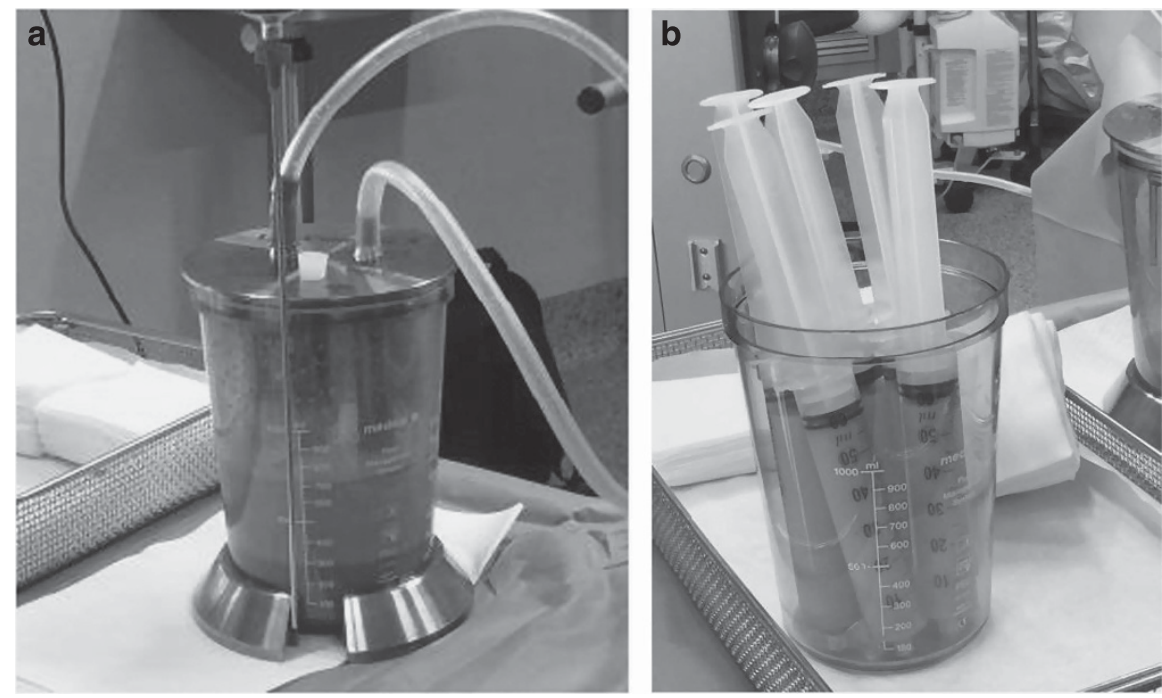

Figure 1 Liposuction. (a) Decantation of fat inside the lipocollector. The solid supernatant fat is separated from the underlying liquid components. (b) Second decantation of fat in 60cc syringes. A full color version of this figure is available at the Spinal Cord journal online.
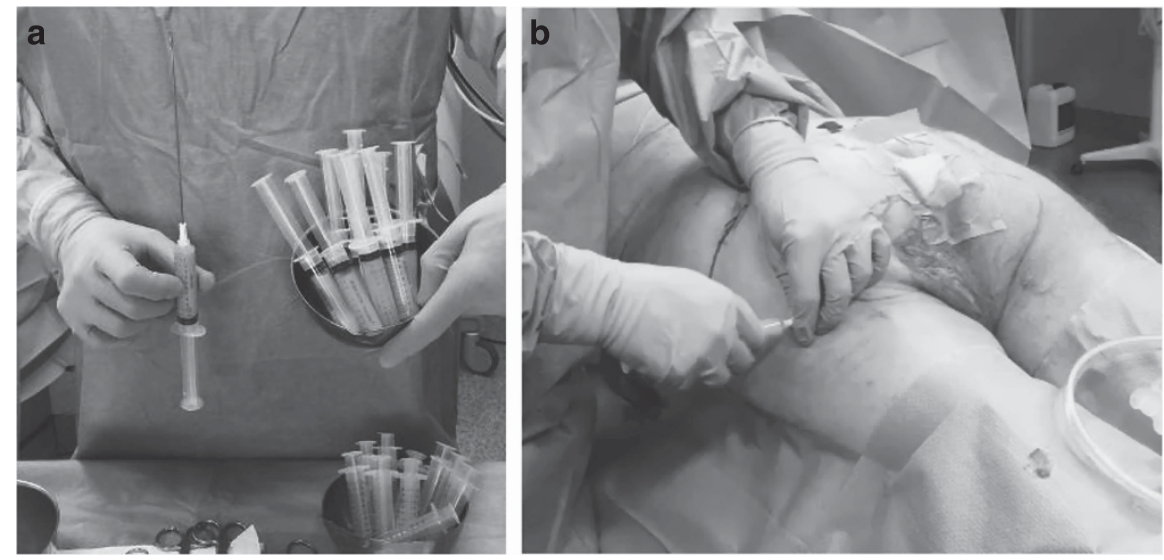

Figure 2 Lipofilling. (a) Transfer of fat into 10cc syringes, with a $20 \mathrm{~cm}$-long needle. (b) Fat grafting in different planes parallel to the skin. A full color version of this figure is available at the Spinal Cord journal online.

We present the preliminary results of lipofilling as a secondary prevention of recurrence of ischial tuberosity and pelvic PrUs in patients with unsatisfactory outcome of previous surgical flap procedures.

\section{MATERIAL AND METHODS}

From January 2013, the lipofilling was proposed to adult chronic SCI patients with history of ischial tuberosity and pelvic PrUs surgery, at risk of recurrence of PrUs due to unsatisfactory skin and adipose tissue thickness. All lipofilling procedures were performed by the same plastic surgeon (Dr Fontet).

\section{Evaluations before the lipofilling surgery}

The following evaluations were performed:

- Weight and body mass index.

- Braden scale for predicting PrUs risk.

- Seating clinic with pressure mapping.

- Photographic assessment.

- Skinfold thickness ('pinch test') with a caliper. The skin is pinched to raise a double layer of skin and the underlying adipose tissue, but not the muscle. Different sites around the ischial tuberosity are measured, the lowest value is reported.

\section{Lipofilling surgery}

Liposuction for retrieval of fat was performed under a local or general anesthesia. A water-jet assisted liposuction method (Harvest-Jet, Human Med AG, Schwerin, Germany) was used, that allows simultaneous irrigation and aspiration of the fat released by water, which is not fragmented or liquefied by physical force. The aspirated fat is filtered and collected in a sterile closed system.

Liposuction. * The fat tissue undergoing liposuction is infiltrated with a tumescent solution containing $0.9 \%$ saline solution with epinephrine 1:1000 using a small-gauge cannula.

* After a few minutes, liposuction of fat with special 3-mm cannulas, through as few ports as possible, under continuous rinse with the tumescent solution at $37^{\circ} \mathrm{C}$ to assist mechanically and rinse the collected fat.

* The procedure is first performed in the patient in the supine position (fat harvesting in the thigh roots and flanks regions), then in the prone position (saddlebags and subgluteal regions).

Decantation. * The aspirated adipose tissue and the irrigation fluid are immediately separated under vacuum conditions by the physical phenomena of buoyancy and gravity. The solid supernatant fat is separated from the underlying liquid (oil, saline solution, vasoconstrictor) components, inside the lipocollector (1L) (Figure 1a). 
Table 1 Characteristic of patients

\begin{tabular}{|c|c|c|c|c|c|c|c|c|c|c|c|c|c|}
\hline Patient & Sex & Age & $\mathrm{SCl}$ & Type & AIS & Level & Time SCl & Weight & Height & $B M I$ & Braden scale & Wheelchair & Cushion \\
\hline 1 & $M$ & 38 & Paraplegia & Upper MNL & $A$ & T01 & 21.1 & 64 & 1.70 & 22 & 16 & Manual & Contoured foam \\
\hline 2 & M & 45 & Paraplegia & Upper MNL & $A$ & T05 & 22.0 & 70 & 1.72 & 24 & 18 & Manual & Air filled \\
\hline 3 & $\mathrm{~F}$ & 36 & Paraplegia & Lower MNL & $A$ & T10 & 18.5 & 52 & 1.57 & 21 & 19 & Manual & Air filled \\
\hline 4 & $\mathrm{~F}$ & 41 & Paraplegia & Lower MNL & $A$ & T10 & 4.4 & 49 & 1.60 & 19 & 17 & Manual & Contoured Foam \\
\hline 5 & $M$ & 53 & Paraplegia & Upper MNL & $A$ & T06 & 30.5 & 74 & 1.78 & 23 & 18 & Manual & Contoured Foam \\
\hline 6 & $M$ & 47 & Tetraplegia & Upper MNL & $A$ & C7 & 13.8 & 89 & 1.86 & 26 & 15 & Manual & Contoured Foam \\
\hline 7 & M & 39 & Paraplegia & Upper MNL & $A$ & T06 & 22.6 & 58 & 1.80 & 18 & 17 & Manual & Contoured Foam \\
\hline 8 & M & 58 & Tetraplegia & Upper MNL & B & C5 & 38.1 & 81 & 1.78 & 26 & 17 & Electrical powered & Air filled \\
\hline 9 & M & 41 & Paraplegia & Lower MNL & B & L01 & 13.9 & 85 & 1.75 & 28 & 19 & Manual & Air filled \\
\hline 10 & $M$ & 44 & Paraplegia & Lower MNL & $A$ & $\mathrm{~T} 10$ & 25.9 & 109 & 1.80 & 34 & 18 & Manual & Contoured foam \\
\hline
\end{tabular}

Abbreviations: AIS, Asia Impairment Scale; BMI, body mass index; MNL, motor neuron lesion; SCI, spinal cord injury; Time SCI, time since SCI.

Table 2 History of pressure ulcers surgery

\begin{tabular}{lccccc}
\hline Patient & $\begin{array}{c}\text { Time since } \\
\text { last ischial } \\
\text { surgery } \\
\text { (months) }\end{array}$ & $\begin{array}{c}\text { Total } \\
\text { number of } \\
\text { surgery }\end{array}$ & $\begin{array}{c}\text { Number of } \\
\text { ischial } \\
\text { surgery }\end{array}$ & $\begin{array}{c}\text { Number of } \\
\text { sacrum } \\
\text { surgery }\end{array}$ & $\begin{array}{c}\text { Number of } \\
\text { trochanter } \\
\text { surgery }\end{array}$ \\
\hline 1 & 5.1 & 1 & 1 & & \\
2 & 17.2 & 4 & 1 & 1 & 0 \\
3 & 11.4 & 5 & 2 & 1 & 1 \\
4 & 0.7 & 1 & 1 & 0 & 2 \\
5 & 1.2 & 2 & 2 & 0 & 0 \\
6 & 1.4 & 2 & 2 & 1 & 2 \\
7 & 1.3 & 6 & 2 & 1 & 0 \\
8 & 0.2 & 5 & 1 & 1 & 1 \\
9 & 5.9 & 2 & 1 & 0 & 0 \\
10 & 7.9 & 4 & 1 & 1 & 0 \\
\hline
\end{tabular}

* The fat is collected in $60 \mathrm{cc}$ syringes held vertically for $10-15 \mathrm{~min}$ for a second decantation (Figure $1 \mathrm{~b}$ ), and then transferred into $10 \mathrm{ml}$ syringes before injection (Figure 2a).

Lipofilling. Patient in the prone position.

* Fat grafting using blunt 2 or 3 -mm cannulas in receiving areas, through tunnels in different planes parallel to the skin, to yield as even a distribution of fat graft as possible (Figure $2 \mathrm{~b}$ ).

* Finally, massage of the injected areas (for reaccommodation of eventual lumps of fat).

The procedure was always kept under $90 \mathrm{~min}$, with the liposuction lasting between 30 and $60 \mathrm{~min}$, and the injection $\sim 10-20 \mathrm{~min}$.

The quantity of fat injected was determined by the surgeon both before and during the surgery, the aim being to obtain a pinch test of at least $5 \mathrm{~cm}$, ideally $6 \mathrm{~cm}$ or more (corresponding to body fat thickness of 2,5 and $3 \mathrm{~cm}$, respectively). The quantity of harvested fat was also determined by the number of receiving sites: both ischial tuberosity areas in all patients, sacral or trochanteric regions when necessary.

The procedure initially required a 5-day hospitalization in our centre. Patients rested in bed for 3 days after the surgery, resumed progressive sitting position on day 4 (usually $30 \mathrm{~min}$, three times a day), attended the seating clinic for cushion prescription, and were discharged the day after. For the last seven patients, the hospital stay was reduced to 2 days, allowing earlier sitting. Progressive sitting was continued at home so as to obtain full sitting between days 10 and 14 .

Patients were also instructed to wear an elastic compression garment (abdominal binding and elastic stockings) for 2 weeks postoperatively to prevent local pain or oedema, and to gently massage the donor and receiving regions daily to prevent desquamation.

\section{Follow-up}

The patients were followed-up on the 14th day, 1st month, 3rd month and 6th month after surgery. An additional visit was proposed for the sake of the study.

The following evaluations were performed:

- Weight and body mass index.

- Seating clinic with pressure mapping.

- Photographic assessment.

- Skinfold thickness ('pinch test') with a caliper (same procedure as before surgery).

- Fat waste is a global assessment by the surgeon that takes into account skinfold thickness and photographic changes.

- Questionnaire on self-perceived skin quality and quality of life using the patient global impression of improvement (PGI-I) questionnaire with the following ratings: very much better, much better, a little better, no change, a little worse, much worse, very much worse. ${ }^{14}$

PrUs were assessed according to the National Pressure Ulcer Advisory Panel's staging system. ${ }^{2}$

\section{RESULTS}

Ten consecutive patients were included. There were eight paraplegic and two tetraplegic patients. Mean age at lipofilling surgery was 44.1 years \pm 6.8 years and mean time since injury 21.1 years \pm 9.4 years. Eight had a complete motor and sensory lesion (AIS A), while two had a complete motor but sensory incomplete lesion (AIS B). Six patients had an upper motor neuron lesion, while four had a lower motor neuron lesion. Their characteristics appear in Table 1.

They had a history of 1-6 PrUs surgery (mean 3.2), including bilateral ischial PrUs in four of them. Time since last ischial surgery was 5.2 years \pm 5.6 years (Table 2). Using the Braden scale, eight patients had mild risks of developing PrUs (scores of 15-18), two patients had no risk (scores of 19-23) (Table 1). Nevertheless, five patients had presented recurrent stage II PrUs after the last surgery.

Fat autologous donor sites for liposuction were abdominal $(n=9)$, thighs and hips (pelvitrochanteric region, $n=7)$, flanks $(n=2)$, breast adipomastia $(n=1)$. Receiving sites for lipofilling were bilateral ischial areas in all, with additional lipofilling of the sacral area in three and of bilateral trochanteric areas in two of them. The pinch tests measurements varied between 1.5 and $4.0 \mathrm{~cm}$, the quantity of fat injected between 60 and $375 \mathrm{cc}$ in the ischial tuberosity areas, and between $50 \mathrm{cc}$ and $200 \mathrm{cc}$ in the sacral and trochanteric areas (table 3).

Mean follow-up time was 16 months (4-24 months) (table 4). Nine patients were regularly followed-up in the outpatient clinic, one (patient no. 8) by telephone contact and exchange of photographs only as he moved after surgery. Short-term medical complications 
Table 3 Preoperative pinch tests measurements and volumes of injected fat at the different sites

\begin{tabular}{|c|c|c|c|c|c|c|c|}
\hline \multicolumn{3}{|c|}{ Pinch test } & \multicolumn{5}{|c|}{ Lipofilling } \\
\hline Patient & Right ischial (cm) & Left ischial (cm) & Right ischial (cc) & Left ischial (cc) & Sacrum (cc) & Right trochanter (cc) & Left trochanter (cc) \\
\hline 2 & 2.0 & 2.0 & 200 & 200 & & 200 & 200 \\
\hline 3 & 2.0 & 2.0 & 375 & 250 & & & \\
\hline 4 & 2.0 & 2.5 & 250 & 150 & & & \\
\hline 7 & 1.5 & 2,5 & 200 & 150 & 80 & & \\
\hline 8 & 2.0 & 4.0 & 200 & 100 & & & \\
\hline 9 & 2.0 & 3.0 & 300 & 200 & 200 & & \\
\hline 10 & 2.0 & 3.0 & 230 & 180 & 150 & & \\
\hline
\end{tabular}

Table 4 Clinical evaluation of ischial tuberosity lipofilling

\begin{tabular}{|c|c|c|c|c|c|c|c|}
\hline Patient & Follow-up (months) & Complications & Pinch test right ischial $(\mathrm{cm})$ & Pinch test left ischial (cm) & Fat waste & Ischial result & Weight change (kg) \\
\hline 1 & 11.9 & None & 4.0 & 3.5 & $25 \%$ & Good & -4 \\
\hline 2 & 11.9 & Stage I & 4.0 & 4.0 & $25 \%$ & Good & +5 \\
\hline 3 & 20.6 & None & 5.0 & 5.5 & $10 \%$ & Excellent & 0 \\
\hline 4 & 17.3 & Stage I & 4.5 & 5.0 & $10 \%$ & Excellent & +1 \\
\hline 5 & 20.8 & Stage II & 3.0 & 2.5 & $75 \%$ left $100 \%$ right & Unchanged & -3 \\
\hline 6 & 22.0 & None & 4.0 & 2.0 & $100 \%$ & Unchanged & -13 \\
\hline 7 & 22.7 & None & 3.5 & 5.0 & $25 \%$ & Good & 0 \\
\hline 8 & 24.0 & None & Unknown & Unknown & Unknown & Good & +4 \\
\hline 9 & 5.4 & None & 5.0 & 5.5 & $10 \%$ & Excellent & -5 \\
\hline 10 & 4.2 & None & 4.0 & 5.0 & $25 \%$ & Good & 0 \\
\hline
\end{tabular}

were limited to local bruises without local or regional infections. Progressive sitting was continued at home so as to obtain full sitting between days 10 and 14 .

Three patients later developed unilateral ischial tuberosity $\operatorname{PrU}$ due to longer sitting position (patients' negligence): two were simple stage I that only required wheelchair cushion adaptation; one was stage II that was healed after additional wound dressing. Patients' weights remained stable over time during follow-ups except for one patient (no. 6) who lost a significant $13 \mathrm{~kg}$. Earlier sitting (day 2 post-operative) did not influence short- or long-term outcome.

For the ischial tuberosity areas, significant improvement of the adipose tissue thickness was seen in seven out of nine patients, with skinfold measurement between 3.5 and $5.5 \mathrm{~cm}$ on each side, and fat waste estimated between 10 and $25 \%$ (Table 4). Clinical and photographic assessments showed excellent to good results in 8 patients (one on photography assessment only) (Figure 3). Unchanged remodelling with fat waste between 75 and $100 \%$ was seen in the remaining two patients. Interestingly, one of these two patients (no. 6) had gained weight $(+3 \mathrm{~kg})$ before the lipofilling as to facilitate the fat harvesting. The result was deemed excellent up to 9 months after surgery with minimal fat waste. Then the man, who was overweight and had difficulties to transfer, went on a diet and lost $13 \mathrm{~kg}$, with $75-100 \%$ fat waste as a consequence.

The outcome was good or excellent in four out of six patients with upper- and all four with lower-motor neuron lesions.

Sacrum fat grafting showed the same (Excellent to Good) results than the ischial regions in the three patients. Trochanteric fat grafting showed good results as well.
Indications for a second lipofilling of the ischial areas were considered in six patients that did not achieve a $5 \mathrm{~cm}$ pinch test at the ischial tuberosity sites (table 4 ).

Pressure mapping before and at follow-up were performed in nine patients. After lipofilling, two patients switched from a contoured foam to an air-filled cushion (table 5). Lipofilling allowed longer sitting times in three patients, including one who was able to resume his professional life. Skin quality was reported improved by nine patients, unchanged by one, worsened by none. Quality of life was perceived improved in six patients, unchanged in 4 others, worsened in none. Surprisingly, four patients spontaneously described 'a better feeling of positioning in their wheelchair', and said they were now able to feel 'when they are not properly seated'. Three patients further reported decrease in pelvic pain. Ischial bursa leakage was cured in one patient. All patients were ready to resume the procedure if necessary.

\section{DISCUSSION}

These first results on secondary prevention of pelvic PrUs with lipofilling can be considered very encouraging, as good results with improvement of adipose tissue thickness were seen in $80 \%$ of patients, with neither short term medical complications nor any recurrence of stages III or IV PrUs during the follow-up period. Most patients described a better quality of life (60\% of patients), longer sitting periods $(30 \%)$ and one patient could resume professional life as a consequence. Our results confirm the good outcomes already described for ischial and sacral lipofilling in the treatment of earlystage pressure ulcer in chronic bedridden patients with neurologic conditions, including patients with SCI. ${ }^{13}$ 

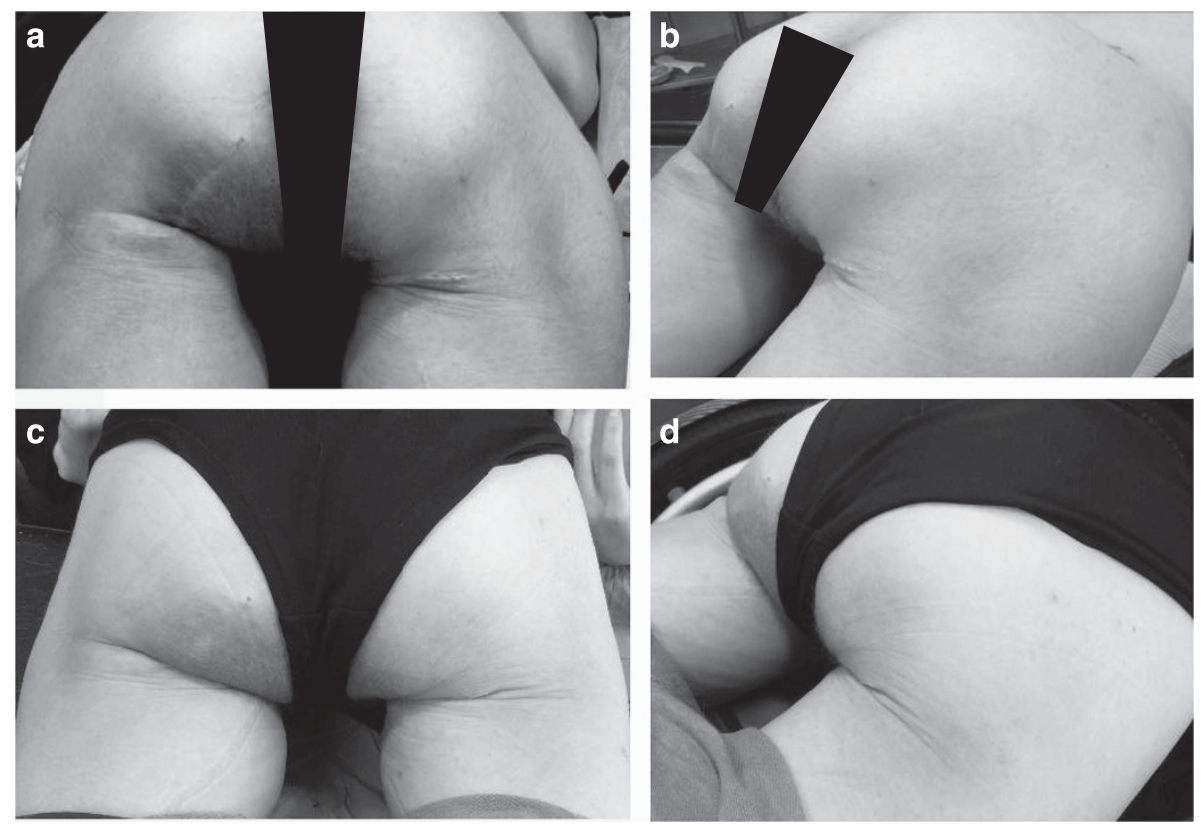

Figure 3 Result of lipofilling in patient $n^{\circ} 4$. Before lipofilling $(\mathbf{a}, \mathbf{b})$ and at 17-month follow-up (c, d). A full color version of this figure is available at the Spinal Cord journal online.

Table 5 Patients' evaluation of lipofilling and sitting changes

\begin{tabular}{|c|c|c|c|c|c|}
\hline Patient & Cushion after lipofilling & Skin quality & Activity change & Quality of life & Sitting feeling \\
\hline 1 & Same & Much improved & Longer sitting times & Much improved & Improved \\
\hline 2 & Same & Very much improved & No & No change & - \\
\hline 3 & Same & Very much improved & Resume professional life & Very much improved & Improved \\
\hline 4 & Same & Much improved & No & Slightly improved & Improved \\
\hline 5 & Switch to air filled & No change & No & No change & - \\
\hline 6 & Same & Slightly improved & No & Slightly improved & - \\
\hline 7 & Same & Much improved & Longer sitting times & Much improved & Improved \\
\hline 8 & Same & Very much improved & No & Very much improved & - \\
\hline 9 & Same & Much improved & No & No change & - \\
\hline 10 & Switch to air filled & Slightly improved & No & No change & - \\
\hline
\end{tabular}

With the advent of liposuction technique in the 1980s, plastic surgeons obtained access to large volumes of adipose tissue. In the 1990s, Coleman described a three staged procedure for fat grafting consisting of: (1) manual lipoaspiration under low pressure; (2) $3 \mathrm{~min}$ of centrifugation at 3400 r.p.m. eliminating the blood, oil and detergents; and (3) reinjection in three-dimensional plan. In creating this technique Coleman pays great attention to the atraumatic handling of adipose tissue which is of paramount importance for autologous fat grafting results improvement. ${ }^{10,15}$ Compared with other filling materials such as silicone implants, the use of adipose tissue has shown to be attractive because it is readily available, inexpensive, host compatible and can be harvested easily and repeatedly as needed without worrying about allergic or foreign body reaction. ${ }^{9}$

But adipose grafts are not just a matter of adipocytes providing volume in the treated area. Adipose tissue has been identified as an abundant source of mesenchymal stem cells. These cells appear to be more resistant and have a major and more prolonged effect on the grafted fat and its surrounding tissues than adipocytes. ${ }^{6-12}$

There is no agreement as to the best way of processing the fat to ensure maximum take and viability of the graft. $^{7}$ We use the decantation technique that, compared to centrifugation, is arguably less selective for cell stems, but has the advantage of being more productive ( 0.71 of fat tissue for 11 of liposuction vs $0.5 \mathrm{l}$ ), and considerably quicker ( $30 \mathrm{~min}$ vs up to $2 \mathrm{~h}$ ) following the use of closed systems that do not require fat manipulation other than a transfer to the injection syringes. ${ }^{11,16}$ Using this technique, the whole procedure is performed in less than $90 \mathrm{~min}$, minimizing the surgery-associated risks for the patients.

Fat harvesting in persons with SCI is usually more difficult than in other non-neurological patients, especially in men (eight in our series) with less fat tissue around the thighs.

Weight control before and after lipofilling is a key issue, as the fat grafts will respond like normal fat and vary in volume according to relative weight gain or loss. As presented in the result section, one patient lost $13 \mathrm{~kg}$ following a diet, and at the same time dramatically wasted all the fat grafted. After breast surgery, fat hypertrophy following weight gain has also been observed, and required breast reduction. ${ }^{17}$ This highlights the necessity of a thorough discussion about weight control that must imperatively take place before the surgery, and is a full part of the patient's education. As a result of the 
beneficial effect of fat hypertrophy, patients with a low body mass index were recommended to gain some weight after the lipofilling, so as to avoid a second fat grafting.

The actual amount of fat grafting per session and per area depends on patient's local morphology. As an empirical rule, the surgeon seeks to double the tissue in a single area. Grafting of larger volumes have been associated with fat resorption and graft necrosis, because of insufficient vascularization, inflammatory response to the grafted fat and cellular damage because of mechanical stresses. ${ }^{11}$

This is one of the reasons why systematic overcorrection in autologous fat grafting should be prevented, especially in those skinny patients that want to gain weight. Instead, different stages of lipofilling with increased amounts of fat tissue can be programmed, depending on the desired result. In our series, the indication of a second lipofilling was considered in five patients, two of whom have been already reinjected with success (unpublished). In breast reconstruction, up to five stages of fat grafting procedures may be required to obtain the desired breast volume. ${ }^{11,18}$

The survival of grafted fat over time is a key issue. For ischial and sacral lipofilling, Marangi et al. ${ }^{13}$ showed significant improvement of subcutaneous thickness at 3 months follow-up in all but one of their 42 patients. For breast lipofilling, it seems that most of the volume loss occurs within the first 3 months after surgery, ${ }^{11,12}$ and that the graft is steadily integrated at the 9th month so that further resorption thereafter is unexpected. ${ }^{10,19}$ At follow-up, the average volume gain varies from 55 to $82 \%$; most authors state that the maximum volume change obtainable in one session is an increase of one breast cup size. $^{11}$

Surprisingly, no article objectifying breast volume change with a follow-up period longer than 1 year exists to date. ${ }^{11}$ Our results with a mean follow-up time of 16 months (4-24 months) are thus fully significant, even though longer follow-up is needed to stand the test of time.

Severity of lesion (AIS A or B) and type of motor neuron lesion (upper or lower) do not seem to influence the outcome.

Recent studies suggest that lipofilling improves overlying skin composition and appearance, with softening of wrinkles and scars, ${ }^{6,8}$ increased elasticity, distensibility, and softness at palpation. ${ }^{13}$ There is evidence that adipose-derived stem cells may transdifferentiate into epithelial stem cells after fat grafting. ${ }^{8}$ This may explain the improvement of skin quality reported by our patients.

Our results of lipofilling in the ischial and sacral areas are similar, which is not surprising as they share the same deep tissue characteristics. By contrast, controlled wound healing of the trochanteric areas leads to layers of scar tissues that need to be treated peroperatively (lysis with a $14 \mathrm{G}$ needle) before the lipofilling. Results so far for the two patients are good.

The assessment of the postoperative results was performed using observation, clinical examination, pinch test and photographic documentation, as in most studies for breast lipofilling. ${ }^{10}$ More objective measurements tools such as three-dimensional photography and laser scanners or magnetic resonance imaging studies are less frequently used, expensive and not suitable for routine clinical practice. $^{10,11,16,19}$ Ultrasound assessment of subcutaneous thickness relative to specific bone landmarks (ischial tuberosity or great trochanter) is an alternative when performed by an experienced radiologist. ${ }^{13}$

Interface pressure mapping is a useful tool for assessment of ischial tuberosity pressure, and changes after therapeutic interventions. ${ }^{4,20}$ In our retrospective study, however, the mapping system was used for clinical purpose only, that is, to assist with individualized wheelchair cushion prescriptions in the seating clinic. The switch from a contoured foam to an air-filled cushion can be considered as an indirect sign of improvement, as it might indicate a better pressure redistribution of ischial pressure in two patients.

Selection of patients for this pioneer study on lipofilling derived from our experience in pelvic ulcers management, and the systematic follow-up after surgery. Besides comprehensive management including seating clinic, we felt that something had to be devised to prevent recurrence of PrUs in those patients presenting with unsatisfactory skin and adipose tissue thickness.

The good or excellent results obtained combined with the safety of the technique and the collateral advantages (better sitting, pain decrease, cure of ischial bursa leakage) gives us every reason to believe that pelvic lipofilling could be used as a primary prevention for PrUs as well. ${ }^{13}$ The first patients have already been included in this new study.

Finally, we strongly believe that education has a pivotal role in the prevention of PrUs. Prevention education includes an emphasis on taking personal responsibility for maintaining healthy skin through personal care, inspection of skin, pressure relief and correct use of prescribed equipment. ${ }^{1-3}$ In our centre, it is done through specific skin management programs for inpatients and carers, attendance to the seating clinic for both in and outpatients, and systematic follow-up of patients. Such programs have been shown to reduce the incidence of PrUs and readmission rates due to PrUs. ${ }^{3,21}$ The discussion prior to the lipofilling helps them better understand the role of cushioning of the ischial tuberosity and its role in the prevention of PrUs.

\section{CONCLUSION}

Pelvic lipofilling is a new and innovative technique aimed at preventing recurrence of PrUs of the ischial, sacral and trochanteric areas in patients with SCI. It is safe, cost-effective, and results in significant improvement of skin quality and quality of life. Following these encouraging results, a new study on the interest of lipofilling as a primary prevention in patients with SCI has been started.

\section{DATA ARCHIVING}

There were no data to deposit.

\section{CONFLICT OF INTEREST}

The authors declare no conflict of interest.

\section{ACKNOWLEDGEMENTS}

We are grateful to Dr DACQUET Vincent, MD, head of the sceptical unit, Fondation Hopale, Berck-Sur-Mer.

1 Consortium for Spinal Cord Medicine Clinical Practice Guidelines. Pressure ulcer prevention and treatment following spinal cord injury: a clinical practice guideline for health-care professionals. J Spinal Cord Med 2001; 24 (Suppl 1): S40-101.

2 National Pressure Ulcer Advisory Panel Prevention and Treatment of Pressure Ulcers: Quick Reference Guide. Revised by NPUAP 2014. Available at: http://www.npuap.org/ resources/educational-and-clinical-resources/prevention-and-treatment-of-pressureulcers-clinical-practice-guideline/ (Accessed 18 May 2015).

3 Regan MA, Teasell RW, Wolfe DL, Keast D, Mortenson WB, Aubut JA. A systematic review of therapeutic interventions for pressure ulcers after spinal cord injury. Arch Phys Med Rehabil 2009; 90: 213-231.

4 Liu LQ, Ferguson-Pell M. Pressure changes under the ischial tuberosities during gluteal neuromuscular stimulation in spinal cord injury: a comparison of sacral nerve root stimulation with surface functional electrical stimulation. Arch Phys Med Rehabil 2015; 96: 620-626.

5 Guihan M, Bombardier $\mathrm{CH}$. Potentially modifiable risk factors among veterans with spinal cord injury hospitalized for severe pressure ulcers: a descriptive study. J Spinal Cord Med 2012; 35: 240-250. 
6 Coleman SR. Structural fat grafting: more than a permanent filler. Plast Reconstr Surg 2006; 118: 108S-120S.

7 Conde-Green A, de Amorim NF, Pitanguy I. Influence of decantation, washing and centrifugation on adipocyte and mesenchymal stem cell content of aspirated adipose tissue: a comparative study. J Plast Reconstr Aesthet Surg 2010; 63: 1375-1381.

8 Derby BM, Dai H, Reichensperger J, Cox L, Harrison C, Cosenza N et al. Adiposederived stem cell to epithelial stem cell transdifferentiation: a mechanism to potentially improve understanding of fat grafting's impact on skin rejuvenation. Aesthet Surg $J$ 2014; 34: 142-153.

9 Eto $\mathrm{H}$, Kato $\mathrm{H}$, Suga $\mathrm{H}$, Aoi $\mathrm{N}$, Doi K, Kuno $\mathrm{S}$ et al. The fate of adipocytes after nonvascularized fat grafting: evidence of early death and replacement of adipocytes. Plast Reconstr Surg 2012; 129: 1081-1092.

10 Khater R, Atanassova P. Autologous fat grafting - factors of influence on the therapeutic results. In: Agullo F (ed). Current Concepts in Plastic Surgery. InTech. 2012, p. 274. Available at: http://www.intechopen.com/books/current-conceptsin-plastic-surgery (Accessed 18 May 2015).

11 Largo RD, Tchang LA, Mele V, Scherberich A, Harder Y, Wettstein R et al. Efficacy, safety and complications of autologous fat grafting to healthy breast tissue: a systematic review. J Plast Reconstr Aesthet Surg 2014; 67: 437-448.

12 Yoshimura K, Asano Y, Aoi N, Kurita M, Oshima Y, Sato K et al. Progenitor-enriched adipose tissue transplantation as rescue for breast implant complications. Breast $J$ 2010; 16: 169-175.
13 Marangi GF, Pallara T, Cagli B, Schena E, Giurazza F, Faiella E et al. Treatment of early-stage pressure ulcers by using autologous adipose tissue grafts. Plast Surg Int 2014; 2014: 817283.

14 Yalcin I, Bump RC. Validation of two global impression questionnaires for incontinence. Am J Obstet Gynecol 2003; 189: 98-101.

15 Coleman SR. Long-term survival of fat transplants: controlled demonstrations. Aesthetic Plast Surg 1995; 19: 421-425.

16 Del Vecchio DA, Bucky LP. Breast augmentation using preexpansion and autologous fat transplantation: a clinical radiographic study. Plast Reconstr Surg 2011; 127 2441-2450.

17 Delay E, Sinna R, Ho Quoc C. Tuberous breast correction by fat grafting. Aesthet Surg J 2013; 33: 522-528.

18 Delay E, Sinna R, Chekaroua K, Delaporte T, Garson S, Toussoun G. Lipomodeling of Poland's syndrome: a new treatment of the thoracic deformity. Aesthetic Plast Surg 2010; 34: 218-225.

19 Horl HW, Feller AM, Biemer E. Technique for liposuction fat reimplantation and long-term volume evaluation by magnetic resonance imaging. Ann Plast Surg 1991; 26 : 248-258.

20 Bogie K, Powell HL, Ho CH. New concepts in the prevention of pressure sores. Handb Clin Neurol 2012; 109: 235-246.

21 Dover H, Pickard W, Swain I, Grundy D. The effectiveness of a pressure clinic in preventing pressure sores. Paraplegia 1992; 30: 267-272. 